\title{
Similar predator aversion for natural prey with diverse toxicity levels
}

\author{
Chouteau Mathieu ${ }^{1,{ }^{*}}$, Dezeure Jules ${ }^{2}$, Sherratt Thomas N. ${ }^{3}$, Llaurens Violaine ${ }^{2}$, Joron Mathieu ${ }^{4}$
}

${ }^{1}$ Laboratoire Ecologie, Evolution, Interactions des Systèmes Amazoniens (LEEISA), USR 3456,

Université De Guyane, CNRS Guyane, IFREMER Guyane, Cayenne, French Guiana

2 Institut de Systématique, Evolution, Biodiversité (ISYEB), UMR 7205 CNRS-MNHN-UPMC-EPHE, Muséum national d'Histoire naturelle, Paris, France

3 Department of Biology, Carleton University, Ottawa, ON, Canada

${ }^{4}$ Centre d'Ecologie Fonctionnelle et Evolutive (CEFE), UMR 5175 CNRS - Université de Montpellier -

EPHE, Université Paul Valéry, Montpellier, France

*Corresponding author : Mathieu Chouteau, email address : mathieu.chouteau@cnrs.fr

\begin{abstract}
:
Müllerian mimicry between chemically defended species arises from selection exerted by predators in which individuals benefit from higher survival when they share the same warning signal. However, despite sharing warning signals, co-mimetic species harbour a diversity of toxins at a range of different concentrations. This variation may affect the rate of predator avoidance learning and therefore the dynamics of mimicry. Here, to understand the nature of mimetic relationships in natural communities of butterflies and moths, we compared protection against predators induced by chemical defences of 13 lepidopteran species belonging to six mimicry complexes. Protection was estimated by quantifying the extent of avoidance learning, using domestic chicks, Gallus gallus domesticus, as model predators. We showed that most co-mimics were avoided at similarly high rates, with the exception of two species eliciting markedly slower rates of avoidance. Assuming our model and natural predators behave similarly and cannot distinguish co-mimics visually, the similar avoidance learning they induce supports the contention that mutualistic relationships among these co-mimetic species might be predominant in natural communities, despite large variation in toxin concentrations. Indeed, by comparing our estimated avoidance learning rate to mean toxin concentration, we found that prey with a two- to three-fold difference in toxin content generated similar avoidance learning indices. This lack of a direct relationship between prey defence level and predator avoidance learning points to alternative evolutionary mechanisms promoting the evolution of high levels of toxins.
\end{abstract}

Keywords : aposematism, Mullerian mimicry, predator aversion, quasi-Batesian mimicry, toxicity 


\section{Introduction}

Müllerian mimicry is an iconic example of evolutionary convergence in which multiple defended prey within a locality evolve similar warning signals. This convergence hinges on the survival benefit associated with the increased abundance of a warning signal. Sharing a warning signal effectively spreads the mortality involved in sampling prey during the education of predators over all co-mimics, resulting in a reduced per capita predation risk (Mallet, 1999; Sherratt, 2008).

The extent to which predators sample unprofitable prey with a given signal depends not just on their innate prior beliefs but also their rate of avoidance learning, which may be higher for prey of higher unprofitability (Skelhorn \& Rowe 2006a).. Therefore, the relative contributions of otherwise indistinguishable co-mimics to predator learning may vary depending on their respective defenses, resulting in either a parasitic or mutualistic relationship (Speed, 1993). The role of variation in prey defenses in the evolutionary dynamics of mimicry has been the focus of much experimental research on predator cognition and theoretical modelling of mimicry systems (Mallet, 2001; Sherratt, 2008; Skelhorn et al., 2016; Ruxton et al., 2018). Fully palatable species clearly act as parasites to their unpalatable (or otherwise unprofitable) models, but the situation is more complex when co-mimetic prey species show different levels of defenses (Rowland et al., 2007; Sherratt, 2008). Indeed, the fitness consequences of differences in defense levels among co-mimics are not trivial to determine, because avoidance learning is affected both by unpalatability (the perception of prey defenses by predators) and by the signal density associated with mimicry (Mallet, 1999; Chouteau et al., 2016; Aubier et al., 2017). Some studies have suggested that prey species eliciting intermediate avoidance learning by predators act as parasites when mimicking better defended species because they reduce the overall rate of predator associative learning (i.e. quasi-Batesian mimicry (Speed, 1993; Rowland et al., 2010)). Other studies have instead suggested that mimics eliciting intermediate avoidance learning contribute more to predator education through increased warning signal abundance than they disturb the association through lower unpalatability, resulting in overall mutualistic interactions (Müllerian mimicry (Müller, 1878; Mallet, 1999; Rowland et al., 2007; Aubier et al., 2017; Pekar et al., 2017)).

To understand the consequences of variation in prey defences, laboratory experiments have been performed with model predators such as domestic chicks and great tits presented with prey items 
containing toxins at variying concentrations (e.g. low $v s$. high concentrations of quinine sulfate, or dedicated animal repellents such as denatonium benzoate). The concentrations used for such experiments were chosen according to preliminary assays confirming that predators could discern them, as shown by fast $v s$. slow avoidance learning (Huheey, 1976; Speed, 1993; Mallet, 1999; Lindstrom et al., 2006; Skelhorn \& Rowe, 2006b; Balogh et al., 2008; Ihalainen et al., 2008). Those experiments constitute a rich literature dissecting the relationships between prey with highly contrasted defense levels. However, the range of variation in the deterrents used in experiments are still difficult to relate to the chemical defenses shown by natural prey species engaged in mimicry relationships in nature. Indeed, experimental vs. natural toxins are different, but more importantly, we continue to ignore to what extent prey species from a natural mimetic community vary in their individual deterrence to predators.

In wild prey, chemical defenses may be synthesized de novo, or sequestered from various sources and used as key precursors or directly stored as toxic compounds. It is known that both the nature of defensive compounds and their amounts vary tremendously within and between mimetic species (Speed et al., 2012; Ruxton et al., 2018). For instance, Ithomiini butterflies are defended by pyrrolizidine alkaloids (Trigo \& Brown, 1990), while co-mimics of the genus Heliconius contain cyanogenic glycosides (Engler-Chaouat \& Gilbert, 2007). Whether this diversity in chemical defenses translates into different learning rates by predators, and hence unequal levels of protection against predators remains untested, but constitutes a key link between laboratory studies and our understanding of natural prey communities.

In the present study, we perform experiments using prey items made from wild-caught samples from species belonging to mimetic communities of chemically-defended butterflies and moths, to determine the distribution of their deterrent effect, through the perception of a model predator. We then investigate how such perception by model predators relates to their toxin content. 


\section{$2 \quad$ Species and mimicry rings}

3 We compared the protection against predation enabled by chemical defenses carried by 13 mimetic

4 species of butterflies and moths from North-Eastern Peru (in the surrounding of Tarapoto - San Martin

5 department), participating in 6 distinct mimicry rings (five species display several morphs, each one

6 mimicking a different community). These species belong to three distantly related clades (Heliconiinae,

7 Danainae and Pericopinae) and are known to possess chemical defenses of different nature (see Table

81 for sample details). As a non-mimetic palatable reference, samples from Anartia amathea

9 (Nymphalinae) were used (DeVries, 1987). Butterflies were field-collected and kept alive in a 4.0L x

$103.0 \mathrm{~W} \times 2.5 \mathrm{H}$ meters outdoor insectary in Tarapoto with ad libitum access to flowers and sugar water.

11 The butterflies were processed as soon as possible (within $12 \mathrm{~h}$ after collection) and used fresh for the

12 experiment described below.

13 Table 1: Variation in protection levels among defended prey species measured with domestic chicks. Here we list the

14 butterfly species tested along with their systematic grouping and mimicry ring(s) (note that some species can display different

15 wing phenotypes and therefore belong to several mimicry rings). We then list the nature of their chemical defense, the number of butterflies of each type tested (nb), their mean CG concentration per mg of dry weightand the estimated CG concentration of crumbs made with their bodies when applicable (mean \pm standard error). We also list the number of chicks experimented on $(\mathrm{nE})$, the estimated mean number of experimental crumbs eaten by these chicks before avodiance is complete (mean $\mathrm{E}+/$ -

$\mathrm{SE}$ ) and the mean total number of experimental crumbs actually eaten (mean $\mathrm{T}+/-\mathrm{SE}$ ).

\begin{tabular}{|c|c|c|c|c|c|c|c|c|c|c|}
\hline \multirow[b]{2}{*}{ Species } & \multirow[b]{2}{*}{ subfamilly } & \multicolumn{2}{|c|}{ Mimcry ring } & \multicolumn{4}{|c|}{ Chemical defence } & \multicolumn{3}{|c|}{ Unpalatability } \\
\hline & & \#1 & \#2 & Chemical & nb & Concentration $(\mu \mathrm{g} / \mathrm{mg})$ & Crumbs GC ( $\mu \mathrm{g} /$ crumb) & $\mathrm{nE}$ & $\mathrm{E}$ & $\mathbf{T}$ \\
\hline Heliconius erato & Heliconiinae & Postman & Dennis-ray & CG & 38 & $0.75 \pm 0.13$ & $4.85 \pm 0.18$ & 6 & $26.90 \pm 6.49$ & $25.16 \pm 5.69$ \\
\hline Heliconius numata & Heliconiinae & Tricolor & Bicolor & CG & 33 & $2.17 \pm 0.12$ & $14.03 \pm 0.57$ & 6 & $8.19 \pm 4.16$ & $8.66 \pm 4.39$ \\
\hline Heliconius burneyi & Heliconiinae & Dennis-ray & & CG & 8 & $2.50 \pm 0.23$ & $16.17 \pm 1.34$ & 6 & $10.72 \pm 2.66$ & $10.16 \pm 2.4$ \\
\hline Heliconius melpomene & Heliconiinae & Postman & Dennis-ray & CG & 24 & $2.53 \pm 0.16$ & $16.36 \pm 0.78$ & 6 & $6.95 \pm 1.79$ & $7.33 \pm 2.06$ \\
\hline Heliconius ethila & Heliconiinae & Spotted & & CG & 7 & $2.69 \pm 0.51$ & $17.39 \pm 1.55$ & 6 & $9.83 \pm 1.85$ & $9.33 \pm 1.67$ \\
\hline Heliconius aoede & Heliconiinae & Dennis-ray & & CG & 12 & $4.26 \pm 0.38$ & $27.55 \pm 1.87$ & 6 & $5.51 \pm 2.45$ & $5.00 \pm 2.23$ \\
\hline Heliconius doris & Heliconiinae & Blue & Dennis-ray & CG & 16 & $4.33 \pm 0.42$ & $28.00 \pm 1.65$ & 6 & $7.55 \pm 1.27$ & $7.16 \pm 1.19$ \\
\hline Heliconius sara & Heliconiinae & Blue & & CG & 12 & $5.58 \pm 0.48$ & $36.08 \pm 2.45$ & 6 & $3.09 \pm 0.69$ & $3.50 \pm 0.76$ \\
\hline Eueides isabella & Heliconiinae & Tricolor & Spotted & CG & na & na & na & 6 & $80.14 \pm 48.66$ & $40.00 \pm 15.27$ \\
\hline Mechanitis polymnia & Danainae & Spotted & & PA & na & na & na & 6 & $46.78 \pm 23.27$ & $33.50 \pm 10.77$ \\
\hline Melinaea mothone & Danainae & Bicolor & & PA & na & na & na & 6 & $10.53 \pm 2.93$ & $10.00 \pm 3.28$ \\
\hline Chetone histrio & Pericopinae & Tricolor & & PA assumed & na & na & na & 6 & $6.91 \pm 1.56$ & $7.16 \pm 1.38$ \\
\hline Chetone hydra & Pericopinae & Bicolor & & PA assumed & na & na & na & 6 & $7.8 \pm 2.55$ & $6.83 \pm 2.21$ \\
\hline Anartia amathea & Nymphalinae & non-mimetic & & none assumed & na & $0.00 \pm 0.00$ & $0.00 \pm 0.00$ & 6 & no learning & no learning \\
\hline
\end{tabular}

Anartia amathea Nymphalinae non-mimetic

$E=$ Estimated crumbs eaten until learning

$T=$ Total crumbs eaten during the 12 trials 


\section{Behavioural experiments}

2 To understand the benefits associated with chemical defenses in natural prey, we sought to determine 3 how variation in defense levels alone (i.e., independently from warning signal) translate into variations in survival through predator aversion learning. Previous experiments have shown that birds are important predators of these Lepidoptera (Mallet \& Barton, 1989; Kapa, 2001; Langham, 2004; Finkbeiner et al., 2012; Chouteau et al., 2016). Therefore, we used the domestic chick (Gallus gallus domesticus) as a standardized predator model to compare aversion to defended prey (Speed, 1999; Skelhorn \& Rowe, 2006a, b, c; Stuckert et al., 2014). Domestic chicks are known to modulate their food intake depending on concentrations of chemical defenses (Skelhorn \& Rowe, 2006b). We thus estimated the rate at which chicks learn to avoid crumbs made from the bodies of toxic butterflies and moths. Experiments were carried out in 12 successive trials, during which, chicks were presented simultaneously with two types of familiar colored food crumbs: one containing extracts from a chemically defended prey and dyed with one color (hereafter referred to as experimental crumbs) and the other without any prey extract and dyed with another color (referred to as control crumbs). After a few trials, chicks generally learned to associate experimental crumb color with chemical defenses and tend to avoid it.

Crumbs were prepared with $2.5 \mathrm{~g}$ of starter chick crumbs (Purina Avemicyn- $\mathrm{A}^{\circledR}$ ) and $1 \mathrm{~mL}$ of colored water $(1 \mathrm{~g}$ of powdered colorants from Industria Lucerico S.A.C. for $100 \mathrm{~mL}$ of water). To prepare experimental crumbs containing butterfly extract of a given species, we ground the bodies of 10 wild caught live butterflies from the same species together, and added $1 \mathrm{~g}$ of this mix to the crumb mix. To prepare control crumbs, the butterfly extract was replaced by $1 \mathrm{~g}$ of starter chick crumb added to the mix. The mix was then air-dried for $12 \mathrm{~h}$ and cut into $1 \times 1 \times 1 \mathrm{~mm}$ crumbs weighting $23.09 \pm 5.43 \mathrm{mg}$ (see estimated toxin concentration of crumbs in table 1). Each crumb eaten corresponds to $\sim 28 \%$ of toxins contained in an equal "bite size" of the natural prey ( $1 \mathrm{~g}$ of butterfly for $3.5 \mathrm{~g}$ of crumb mix) . Both experimental and control crumbs were prepared in both green and orange colorings.

Ten-day-old chicks born and raised in commercial aviary farms, and fed from birth with Avemicyn chick crumbs, were kept in a $3 \times 2$ m outdoor enclosure in Tarapoto (Northeastern Peru) with ad libitum access to water. The three days before the experiment, chicks were fed three times daily with a 
1 simultaneous presentation of orange and green control crumbs in a white tray in an experimental arena.

2 This training enables the chicks to acclimate to the experimental arena and overcome any crumbs color

3 preference initially present. The experimental arena was composed of two adjacent $45 \times 35 \mathrm{~cm}$

4 subsections with a blue floor and water dispensers, enclosed with chicken mesh. The experimental chick was placed in one subsection and a companion chick in the adjacent subsection in order to limit stress. Tested chicks were deprived from food $2 \mathrm{~h}$ before the experiment.

7 For each trial, a $35 \times 20 \mathrm{~cm}$ white tray containing 20 orange and 20 green crumbs of distinct colors positioned alternatively along an $8 \times 5$ grid was placed in the experimental section. The first trial (named Trial 0 in fig. 1) was performed by using only control crumbs (i.e. 20 orange and 20 green palatable crumbs) and enabled to verify that no preference for a particular color of crumbs was present for the tested chick. The tray was removed from the experimental section as soon as 20 crumbs were attacked by the chick (sum of the orange and green crumbs pecked or eaten). During each trial, a portion of food was also given to the companion chick. Experimental trials occurred the same way as trial 0 but with all 20 green control crumbs being replaced by green experimental crumbs. Each experimental chick performed 12 successive experimental trials, with each trial separated by 30 min intervals. Six different chicks were used for each prey species, so that the design was fully nested. Colors used for experimental and control crumbs (green and orange) were switched for half of the chicks ( 3 per butterfly species) to allow us to control for any effect of innate preference for one of the colors. The ethical committee for animal welfare of the National Museum of Natural History (ethical declaration $n{ }^{\circ}$ 68-064) validated this experimental design.

\section{$\underline{\text { Ethical Note }}$}

The experimental design was evaluated by the ethical committee Cuvier from the National Museum of Natural History (Paris, France), which provided a 'Favourable' opinion, describing the impact on the animals as 'Light' (see licence number 68-064 attached). Our experiment is thus conforming to EU legal requirements.

Number of individuals involved in the study: Following the general 'three R rules' (Replacement, Reduction and Refinement), we used the minimum number of chicks per butterfly species tested to 
obtain a sufficient statistical power ( $n=6$ per butterfly species). Only 84 chicks were thus used in this study, with a balanced sex-ratio. Chicks were circa. 10 days of age

Origins of the chicks used in the experiments: Domesticated chicken are bred in many homes in this area of Peru and were thus bought in the local market, located less than 10 minutes away from the location of the experiments.

Disposal of the chicks used after the experiments: After a couple of days after the experiments, the chicks were donated to nearby families already raising chickens.

Disturbance: These domesticated chicks were placed in conditions highly similar as those encountered in the breeding facilities they came from, so that we think these conditions did not induce any particular disturbance.

Potentially harmful manipulations: In this behavioural experiment, we did not perform any harmful manipulation, except that half of the food provided in the experiments contained butterfly extracts that may contain some chemical compound inducing deterrence. As shown in the results of our manuscript, most chicks avoided food containing chemically-defended butterfly very rapidly, and therefore ingested a very limited amount of food containing deterring compounds. Chicks thus generally exhibit no residual signs of the experiments.

Distress or pain: In rare occasions $(n=4)$, some chicks did not immediately react to the chemical compounds of the butterflies and continues to eat food containing butterfly extracts, and could display signs of stress. We thus used the following rule: if a chick display sign of prostration (do not move, has the neck located within the shoulders and closed eyes) for more than 3 minutes, we immediately stopped the experiment and moved the tested chicks back to the large $3 \times 2 \mathrm{~m}$ outdoor enclosure. These chicks then recovered within a couple of minutes after being stopped eating food with butterfly extracts and do not display any residual signs afterwards. Each chick was used only once for the experiment and chicks that displayed prostration behavior were not tested again. 


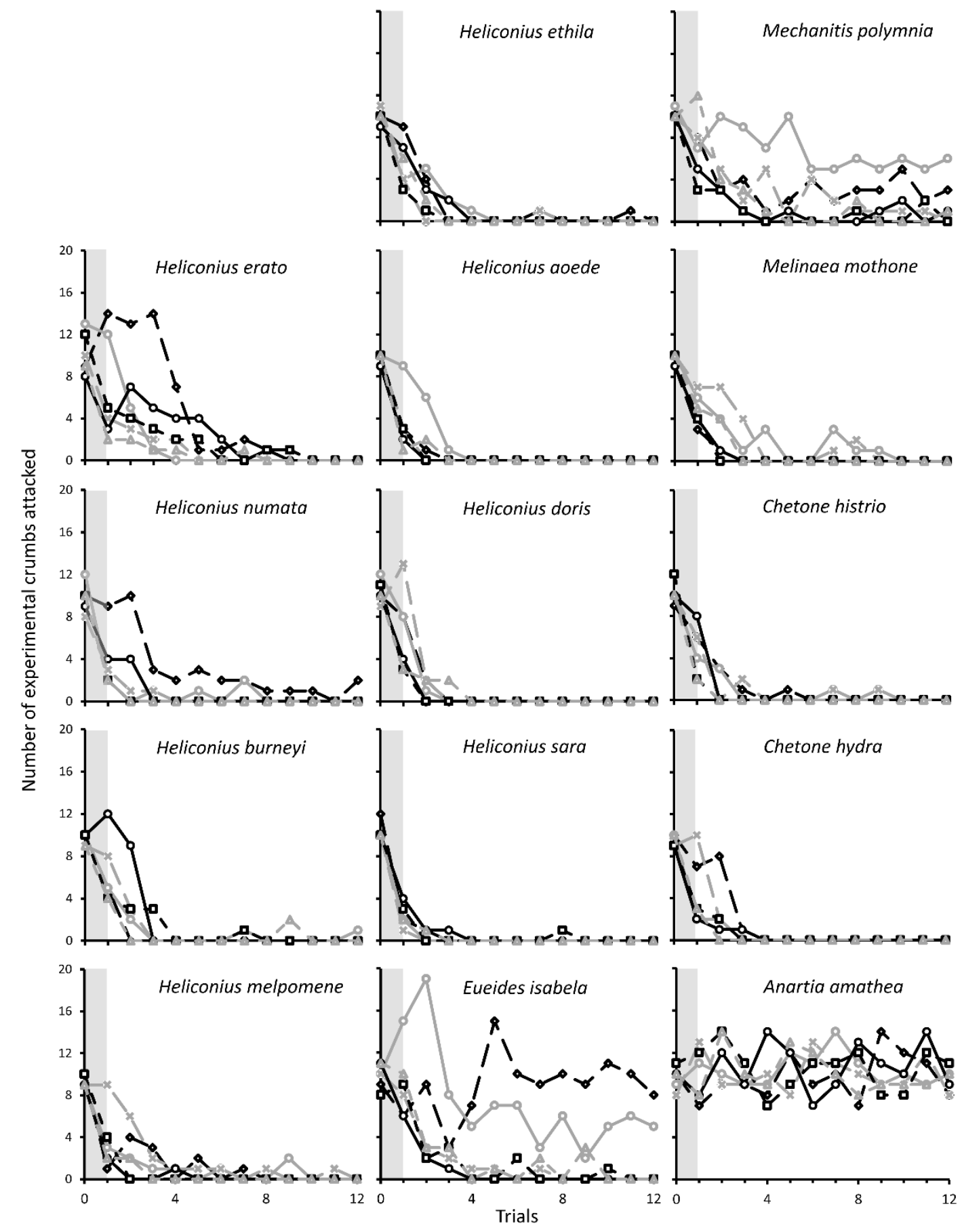

2 Figure 1: Model predator association learning. Attacks by individual chicks on experimental butterfly crumbs through the experiment trials (beginning at trial 1, white area). Each curve represents the change in consumption of an individual chick presented with green (grey curves) or orange (black curves) experimental crumbs. Trial 0 (grey area) was performed using only control crumbs of both colours to confirm chicks did not have a preference for one colour. 


\section{$2 \quad$ Statistical analysis}

3 Model fitting was performed in R version 3.1.3 (R Development Core Team, 2013). Our domestic

4 chicks generally decreased the number of unpalatable crumbs sampled in successive trials, until reaching a stable minimum attack level, mirroring a classical avoidance learning curve (Speed, 1999; Skelhorn \& Rowe, 2006a). A common way for analyzing avoidance learning is through fitting a generalized linear mixed model (GLMM) with the individual predator as a random effect, assuming a binomial error variance since each crumb presented was either attacked or not (e.g. see Kazemi et al., 2014; Sherratt et al., 2015). However, one of the properties of the standard logit model GLMMs is that they necessarily assume a long-term asymptote attack probability of 0 or 1 , yet we wished to determine whether the long-term asymptotic consumption rate of chicks feeding on treated crumbs differs from 0. To obtain biologically meaningful avoidance learning parameters we therefore fitted a family of exponential consumption models by non-linear least squares. Model fitting was performed using the nlme function of the nlme package (Pinheiro et al., 2017) which allowed us to also estimate nested random effects. To fit meaningful models, the analysis was restricted to the consumption of crumbs made from those species butterfly that were increasingly avoided by chicks (i.e. all species but the $A$. amathea control). Here the number of experimental (unpalatable) crumbs eaten was treated as the dependent variable, trial number was a covariate predictor, crumb color was a fixed effect, and both chicken ID and butterfly species were treated as random factors, with chicken nested within butterfly species. In addition to the crumb colour term (which proved to be non-significant), the most general learning model took the form of experimental crumbs eaten per trial $=a+b \cdot e^{-c . t r i a l}$ where $a, b$ and $c$ are the estimable parameters such that $(a+b)$ is the y-intercept (when trial $=0$ ), $a$ is the long-term feeding rate asymptote (when trial $\rightarrow \infty$, assuming $c$ is positive) and $c$ is the learning parameter. The self-starting function SSasymp was used to facilitate model convergence. For simplicity, the random effects component was assumed to affect either parameter $a, b$ or $c$. Normality and homogeneity of variance of residuals around the fitted model were evaluated through examination of the residual plots. The importance of terms in the model was assessed through log likelihood ratio (LR) tests and Akaike Information Criteria (AIC). 


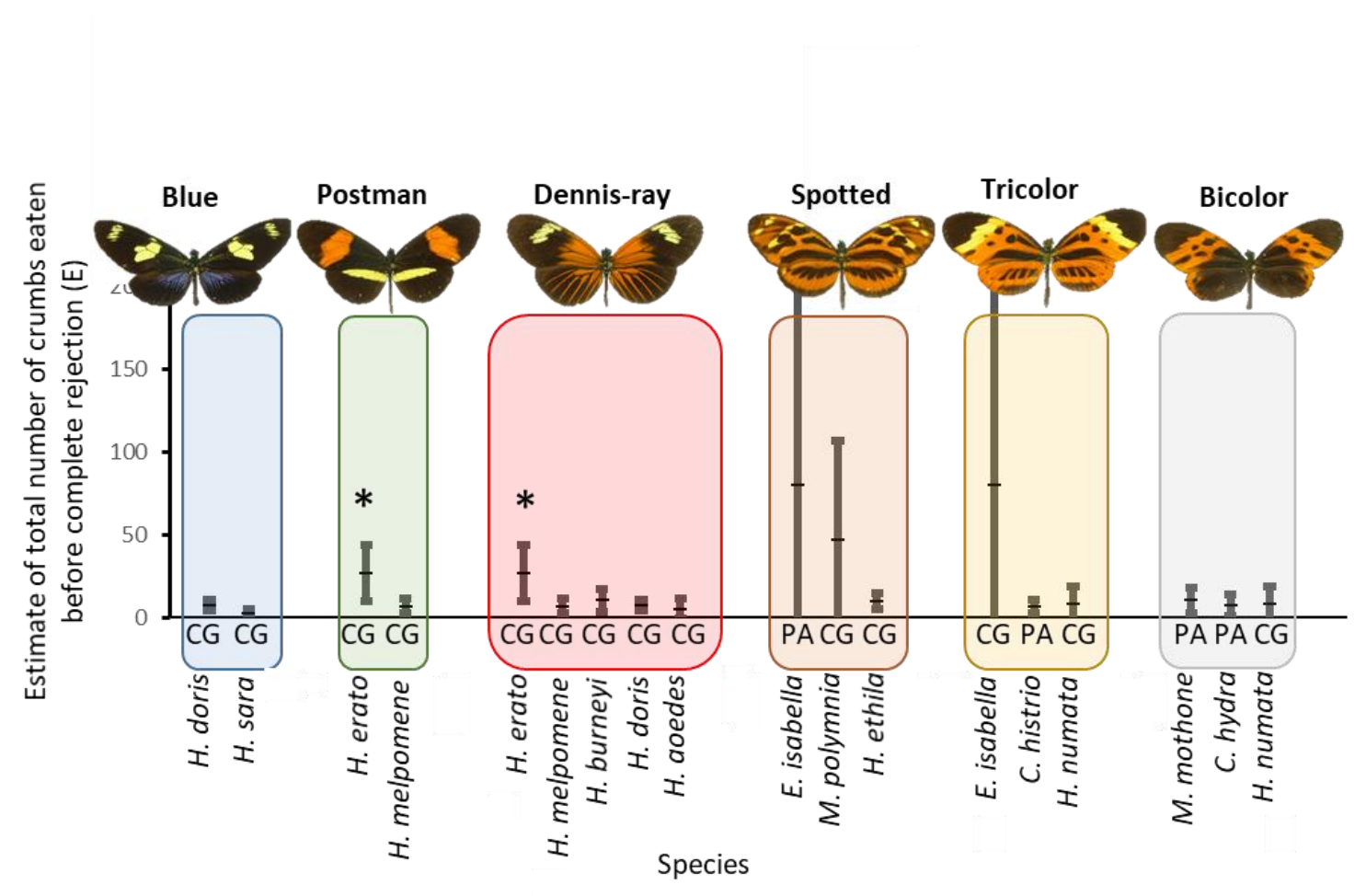

3 Figure 2: Variation in predator avoidance learning generated by species within and across mimicry rings. Species showing significant differences in the rate of avoidance learning (mean $E$ and $95 \%$ confidence interval), from all of their comimics (or one mimic; horizontal bar) are indicated with asterisks: ** $\alpha=0.05, * \alpha=0.10$. The color squares delimit the species part of a mimicry rings, and the butterfly picture the mimetic warning signal. Chemical identity of defenses is indicated for each species: CG for cyanogenic glycosides and PA for pyrrolizidine alkaloids.

9 After fitting the above over-arching model to the consumption of crumbs derived from species believed to be unpalatable, we found that we could not reject the null hypothesis that the long-term feeding rate (a) of chicks was zero - see Results. Instead, our most parsimonious model was one in which the rate of consumption of an unpalatable crumbs simply declines exponentially over trials (following $b \mathrm{e}^{-c \text { trial, }}$, with $b$ representing the initial rate of consumption at trial 0 and $c$ representing the rate of avoidance learning). Since the random component (chick nested within butterfly species) of the learning parameter (c) was also highly significant in the above model, we sought to obtain parameter estimates for individual birds feeding on the crumbs derived from given butterfly species. To do this, we separately fitted the same family of exponential models to the consumption data of each and every chick using the nlsList function of the nlme package. As with our overarching fitted models above, the long-term 
consumption asymptote $a$ was significantly different from 0 in only 3 of the 78 chicks tested (well within the expected type I error rate if the null hypothesis were true) and these cases were distributed across different butterfly species. We therefore also fitted the most parsimonious model namely b.e ${ }^{c . t r i a l}$ to the individual crumb consumption data. Since the estimate of $c$ for each chick was consistently (and often significantly) postive, the estimated cumulative long term consumption of unpalatable crumbs of individual chicks after removing the number of palatable crumbs consumed at trail $0(E=$ $\left.\left(\sum_{0}^{\infty} b e^{-c \text { trial }}\right)-b\right)$ will be $b\left\{\mathrm{e}^{c} /\left(\mathrm{e}^{c}-1\right)-1\right\}$. We view this composite parameter $E$ as an appropriate and biologically meaningful indicator of the rate of avoidance learning since (i) it is trial independent and can be applied to identify the avoidance rate of those treated crumbs that have not been completely avoided by the end of the experiment and (ii) it relates directly to Müller's argument that birds should consume a fixed number of a given unpalatable prey type before avoidance learning is complete. Naturally, in cases where avoidance learning was largely complete by the end of 12 trials, then one would expect that the estimate of $E$ would closely match the total number of unpalatable crumbs consumed by a given bird ( $T$ ) over the course of the experiment, which is precisely what we find (see Table 1). To test for variation in the unpalability parameter $E$ between all butterfly species and also among species that fall part of a mimicry ring, we used one-way ANOVAs on the individual estimates followed by a Tukey honestly significant difference (HSD) post hoc test to identify pairwise differences in $E$ among species. In the study area, some of the species show distinct morphs participating in distinct mimicry rings (Table 1). Colour pattern variation is controlled by simple genetic switches in those species, but morphs are otherwise not differentiated across the genome (Joron et al., 2006; Baxter et al., 2010; Counterman et al., 2010) and share common general life histories (Brown, 1981; Joron, 2005). Therefore, we assumed that distinct morphs within species did not vary significantly in defense.

Since trial 0 involved entirely palatable crumbs so as to start with an intercept of approximately 10 , we have fitted the same set of models to our data with trial 0 starting at the first presentation of unpalatable crumbs (this implies $\left.\mathrm{E}=b \mathrm{e}^{c} /\left(\mathrm{e}^{c}-1\right)\right)$. This analysis is presented in our Supplementary Materials. Since the estimates of $E$ with and without the first trial considered are highly correlated $\left(\mathrm{R}^{2}=0.98, \mathrm{P}<0.001\right)$ and the same general conclusions apply, we focus on the former analysis here. 


\section{$1 \quad$ Relationship between prey defense level and avoidance learning by predators}

2 Protection from predation, estimated using the learning parameter $E$ was compared to the average concentration of defensive chemical compounds (hereafter referred to as defense level) measured in samples of the same species. This analysis was restricted to the eight studied species of the genus Heliconius since 1) they are defended by the same chemical compounds: cyanogenic glycosides (CG) (Merrill et al., 2015) and 2) the mean CG concentration (measured in $\mu \mathrm{g}$ of $\mathrm{NaCN}$ per mg of dry butterfly) is already available from different wild-caught individuals from the exact same localities we used for this study (see (Arias et al., 2016b) for more details). In brief, to measure the CG concentration of each individual, (Arias et al., 2016b) have extracted all CGs (regardless of their chemical diversity) by performing a hydrolysis under harsh acidic conditions. This step frees cyanides from biological tissue and traps them in solution as $\mathrm{NaCN}$. $\mathrm{NaCN}$ concentration $\left(C_{N A C N}\right)$, was then quantified using a colorimetric method (Arias et al., 2016b). The average concentration of CG for each of the eight Heliconius species was obtained using at least 5 individuals per species (see Table 1).

To assess the relationship between defense levels and aversion, we compared the fit of three candidate models linking measures of concentrations of defensive compounds $\left(C_{N A C N}\right)$ to avoidance learning $(E)$ : an intercept-only model (no relationship), a linear model (proportional relationship) and an exponential model (geometric relationship). Models were fitted using the least squares method of the nls function in the R nlme package (Pinheiro et al., 2017) and their relative parsimony was assessed through log likelihood ratio tests and Akaike Information Criteria (AIC).

To assess whether differences in defense level cause differences in aversion by predators, we assessed whether there were significant differences between species of butterflies in defense levels and behavioural responses. One way ANOVAs using Welsh's test, followed by a Games-Howell post hoc tests was used when $C_{N A C N}$ was ther response variable to account for the non-homogeneity of variances (Levene's $\mathrm{W}_{7,142}=3.84 ; \mathrm{p} \leq 0.001$ ) and unequal sample size between groups. One-way ANOVA followed by Tukey HSD post-hoc tests was performed on $E$. 


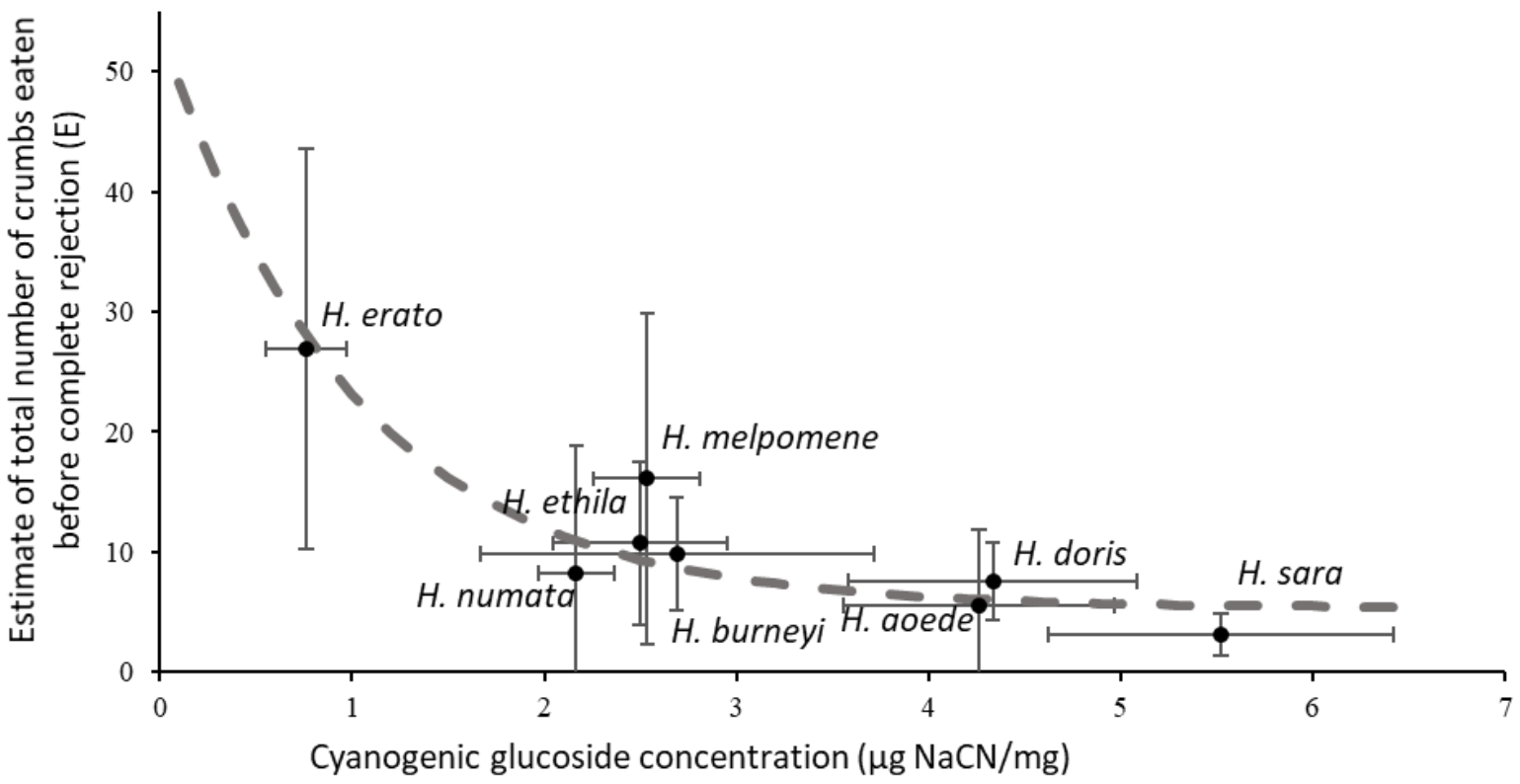

1

2 Figure 3: Relationship between defense level and avoidance learning in eight Heliconius species. Avoidance learning 3

\section{$7 \quad$ Results}

\section{$8 \quad$ Estimation of avoidance learning using chicks}

9 All butterfly species but A. amathea (the palatable control) induced in the chicks a clear decline in the

index in tested chicks $(E)$ foraging on crumbs made of butterflies whose cyanogenic glycoside concentration $\left(C_{N A C N}\right)$ has been estimated. Means and 95\% confidence intervals are shown for each species of butterfly tested. The dashed curve represents the best model describing the relationship between defence and avoidance learning. consumption of experimental crumbs over time which appear to assympote towards zero (see Figure 1). A preliminary comparison of our fitted exponential models suggests that the most parsimonious models involve the fixed effects of trial (model 1 vs model 7, LR $=2074.42, \mathrm{P}<0.001$ ) but not crumb colour (model 1 vs model $2, \mathrm{LR}=1.56, \mathrm{P}=0.212$ ) while a two parameter learning model is superior to the three parameter involving a non-zero asymptote (model 1 vs model $3, \mathrm{LR}=18.87, \mathrm{P}<0.001$ ) - see Table 2. In addition, there was evidence of significant variation in the rate at which individual chicks avoided treated crumbs made from different butterfly species (model 1 vs model $6, \mathrm{LR}=955.3, \mathrm{P}<$ $0.001)$ 


\begin{tabular}{|l|l|l|l|l|}
\hline Model number & $\begin{array}{l}\text { Model for treated prey } \\
\text { consumption over trials } \\
\text { (a, b, c, f parameters) }\end{array}$ & $\begin{array}{l}\text { Random effect } \\
\text { parameter } \\
(\sim \text { species/bird) }\end{array}$ & Df & AIC \\
\hline 1 & $b^{*} \exp \left(-c^{*}\right.$ trial) & $c$ & 5 & 3166.7 \\
\hline 2 & $b^{*} \exp \left(-c^{*}\right.$ trial) $+f^{*}$ colour & $c$ & 6 & 3170.3 \\
\hline 3 & $a+b^{*} \exp \left(-c^{*}\right.$ trial) & $c$ & 6 & 3187.6 \\
\hline 4 & $a+b^{*} \exp \left(-c^{*}\right.$ trial) & $a$ & 6 & 3647.5 \\
\hline 5 & $a+b^{*} \exp \left(-c^{*}\right.$ trial) & $b$ & 6 & 4080.1 \\
\hline 6 & $b^{*} \exp \left(-c^{*}\right.$ trial) & - & 3 & 4118.0 \\
\hline 7 & $a$ & $a$ & 4 & 5239.1 \\
\hline
\end{tabular}

Table 2: Statistical analysis of avoidance learning experiments. A range of candidate non-linear models fitted to the consumption of crumbs over time by chicks. These models involved both fixed and random effects. The most parsimonious model was one in which consumption simply declined exponentially, but there was also significant variation in the rate of avoidance learning of experimental crumbs made from different butterfly species by individual chicks.
5

6 Having established evidence that avoidance learning occurs and that there is significant variation in the

rate at which crumbs made from different butterfly species are avoided by chicks, we now focus on comparing the rates at which different butterfly species are avoided. Avoidance learning $(E)$ - estimated from fitting the most parsimonious model b.e $e^{-c . t r i a l}$ to the consumption data of each and every chick was variable among defended butterfly species $\left(F_{12,65}=2.11 ; p=0.027\right)$. The species eliciting the fastest learning, sometimes within the first trial, were Heliconius sara $(E=3.1 \pm 0.7 \mathrm{SE})$ and $H$. aoede $(E=5.5 \pm 2.4)$. Learning rate was much slower for Mechanitis polymnia $(E=46.8 \pm 23.2)$ and Eueides isabella $(E=80.1 \pm 48.6)$. The latter species was the only one for which unpalatability $(E)$ was found significantly different from some others $(H$. sara and $H$. aoede at $p=0.05)$ when all butterflies are analysed jointly (i.e. mimicry rings were not considered).

\section{Variation in avoidance among species within mimicry rings}

Estimating avoidance learning with a chick predator enabled us to compare the protective effect induced by the toxin content of the different prey species. Here, we compared the strength of chemical defense in Heliconiinae, Danainae and Pericopinae relying on different toxins and belonging to the same mimicry rings.

When comparing among co-mimics, protection was overall found to be relatively similar (Figure 2), even when species belong to distantly-related clades. Only the slower levels of avoidance learning 
found for $H$. erato resulted in two mimicry rings showing significant variation in avoidance learning among species : 'postman' ring $\left(F_{1,10}=8.782 ; p=0.014\right)$, and 'dennis-ray' ring $\left(F_{4,25}=6.456\right.$; $p<0.001)$

\section{Relationship between the level of prey defenses and avoidance learning by predators}

Focusing solely on the Heliconiinae butterflies which all rely on cyanogenic glycosides for defense, we investigated the relationship between mean toxicity levels for each species (i.e. $C_{N A C N}$ ) and the resulting protection from predator as estimated with $E$. By comparing different statistical models, we found that an exponential decay model (asymptotic decrease) provided the best fit to the data (AICs: intercept only model 51.50; linear model 44.84; exponential model 34.67) and that the exponential model explained more variation than the linear model with the same number of terms $\left(F_{1,5}=37.191, p=0.002\right.$, see Figure 3).

As previously described in Arias et al.(2016b), variations in $C_{N A C N}$ can be clustered into three significantly different groups $\left(F_{\text {Welch } 7,36.75}=30.091 ; p<0.001 ;\right.$ Figure 2$\left.): 1\right)$ H. erato was the least toxic, with a significantly lower $C_{N A C N}$ than all other species $\left(C_{N A C N}=0.75 \pm 0.13 \mu \mathrm{g} / \mathrm{mg}\right.$; intercluster post hoc $p \leq 0.001) ; 2) ; H$. numata, $H$. melpomene, $H$. ethila and $H$. burneyi formed a group with intermediate $C_{N A C N}\left(C_{N A C N}=2.17 \pm 0.12\right.$ to $2.69 \pm 0.51 \mu \mathrm{g} / \mathrm{mg}$; intracluster post hoc $p \geq 0.900$; intercluster post hoc $p \leq 0.043) ; 3$ ); H. aoede, H. doris and H. sara were the most toxic, with highest $C_{N A C N}\left(C_{N A C N}=4.26 \pm 0.38\right.$ to $5.58 \pm 0.48 \mu \mathrm{g} / \mathrm{mg}$; intracluster $p \geq 0.072$; intercluster $\left.p \leq 0.043\right)$.

By contrast, prey protection estimated here by chick learning behavior revealed only two main clusters of species $\left(F_{7,40}=5.173 ; p<0.001 ;\right.$ Figure 3$)$ with a single species, . erato, on the one hand, generating avoidance learning at a significantly slower rate than all other species (intergroup post hoc $\mathrm{p}<0.019$ ). All other species where $C_{N A C N}$ was estimated were avoided at a similar speed (intragroup post hoc $p \geq 0.122)$.

We showed that $E$ initially decreased with increasing toxicity $C_{N A C N}$ (Figure 3 ). However, above a threshold of toxicity (here detectable with $H$. numata containing $C_{N A C N}=2.17 \pm 0.12 \mu \mathrm{g} / \mathrm{mg}$ ), E no 


\section{Discussion}

longer decreased. This asymptotic non-linear relationship between $C_{N A C N}$ and $E$ suggests that above a threshold of around $C_{N A C N}=2 \mu \mathrm{g} / \mathrm{mg}$, a two or three-fold increase in concentration of chemical defense level provides similar rate of avoidance learning.

\section{Are diverse communities of mimetic prey influenced by their variation in toxicity?}

By studying the behavior of a model avian predator faced with the toxins derived from wild butterflies, we provide new insights into the relationships linking prey defense and predator learning in natural communities. First, our experimental data provide very little evidence for the existence of a non-zero asymptote for crumbs prepared from our butterflies. This is important because the theory of quasiBatesian mimicry specifically depends on the assumption of a non-zero asymptote (Speed, 1993; Mallet and Joron, 1999), otherwise even moderately defended prey would ultimately not be parasitic on the better defended prey they resemble. Our results also suggest that despite large variation in chemical defences between prey types, most are avoided at similar rates. Indeed, the non-linear asymptotic relationship between toxin concentration and behavioural response results in a situation where severalfold variation in chemical concentrations in prey items does not translate into proportional variation in protection from our model predators. Only in the range of low to moderate defense level does an increase in defense level translate into faster avoidance learning for our model predator. This confirms the capacity of our chick predators to perceive and discriminate between some levels of toxicity. Yet for higher defense levels, avoidance learning quickly saturates and often occurs after a single trial.

Many dose-response relationships in toxicology are non-linear (often logit or probit; Demidenko et al., 2017), and so that a saturating behavioural response can be expected. However, the position of defenses contained in butterflies from natural communities with respect to the saturation threshold was unknown. The majority of the tested species fall above the saturation threshold, where variation in toxin titres does not generate much variation in predator response. Assuming that the behavior of domestic chicks is representative of natural predators, parasitic (quasi-Batesian) mimetic relationships (Rowland et al., 2010) may be expected to apply to at most a small proportion of the species composing this natural 
community (those eliciting slow learning), while most species would be sufficiently toxic to elicit efficient learning by predators.

This result leads us to suggest that species in the natural communities may have a role in their respective mimicry ring that is not determined primarily by their relative toxicity, but by other ecological or phenotypic differences. Indeed, because we purposefully prevented access to visual signals in our experiments, our results reveal the response of predators to the taste (or toxicity perception) component of associative learning, which amounts to assuming indistinguishable warning signals between prey species. Under this assumption (which may hold for instance when warning patterns are widely generalized among co-mimics or when mimics are extremely similar), then co-mimics with different levels of toxicity make a similar per capita contribution to the predator's avoidance learning. Assuming our model predator behave consistently with natural predators, this suggests that relationships at the community level are likely to be largely mutualistic, and that differences in mimicry roles (model vs. mimic) would be determined primarily by species abundance in contrast to Batesian mimicry expectations (Finkbeiner et al., 2018). Within these mimicry rings, selection on colour pattern is thus likely to promote resemblance to the warning signal of the most abundant species, rather than of the most toxic one (Mallet, 1999).

Nevertheless, co-mimetic species may differ in other traits influencing predator avoidance learning. Phenotypic differences such as variation in signal quality (wing pattern, flight movements, and imperfect resemblance), variation in the modalities of toxin presentation, in additional signaling modalities, or in habitat preferences may also play a significant role in the evolution of mimetic color patterns within natural communities (Beccaloni, 1997; Skelhorn \& Rowe, 2005; Lindstrom et al., 2006; Skelhorn \& Ruxton, 2008). Although crumb color was unimportant in our experiments, we cannot rule out interactive effects of toxin and phenotype on aversion learning. For example, classic work by Gittleman \& Harvey (1980) indicated that domestic chicks learned more quickly to avoid unpalatable crumbs when they were conspicuous, so differences in toxicity might generate differences in aversion learning only when associated with particular phenotypes. Finally, we acknowledge that spatial and temporal variation in predation pressure (Chouteau \& Angers, 2011; Mappes et al., 2014), in mimetic community composition or in unpalatability (e.g. depending on hostplant secondary defenses and 
availability) might all affect aversion learning by predators and could therefore impact the nature of mimetic relationships.

\section{What drives the evolution of variations in toxicity?}

Understanding how natural selection exerted by predators drives the evolution of defense levels in aposematic prey is not straightforward. In most cases, chemical defense cannot be detected prior to attack. Therefore, investment in individual defense level is not predicted to increase in response to natural selection on attack avoidance. However, aposematic insects can sometimes survive predation attempts (Wiklund \& Järvi, 1982; Sillén-Tullberg, 1985; Chai, 1996) and predators can often taste and release prey selectively based on the perception of harmful chemicals (Pinheiro, 1996; Gamberale-Stille \& Guilford, 2004; Skelhorn \& Rowe, 2006a, c). For instance, beak marks are often seen on the wings of aposematic butterflies indicating previous attacks by predators (Smith, 1979; Mallet \& Barton, 1989; Ohsaki, 1995) and many defended prey posess traits which increase the chance of surviving an attack, either by increasing tissue resistance or by increasing the chance of being taste-rejected without harm (Skelhorn \& Ruxton, 2008). For instance, storing toxins in the wing integuments (Nishida, 1994, 2002), or excreting toxins when handled (such as the thick and bright yellow haemolymph secreted by labybirds (Holloway et al., 1991) or the voluminous foam produced by Chetone moths) may discourage handling by predators and improve survivorship. Therefore, surviving attacks can be enhanced by individual toxin contents, and selection may favor traits in the prey that increase the rapid perception of their defenses by predators. Here, the fact that most species display CG concentrations above the sufficient amount for associative learning ( $2 \mu \mathrm{g} / \mathrm{mg}$ in our experiement) might reflect the importance of being sufficiently defended to derive individual benefits from chemical defences.

The evolution of higher toxin contents above a certain threshold also points at other evolutionary forces shaping the level of defense. Increased toxicity may provide increased protection against toxin-resistant predators (Williams \& Brodie, 2003; Trigo, 2011) or may be related to other process not related to predator deterrence (Speed et al., 2012). High toxin loads may be expected (1) if they provide protection against parasitoids (Campbell \& Duffey, 1979; Barbosa et al., 1991; Sime, 2002; Lampert et al., 2008 but see 2010), (2) if they are a by-product of host-plant adaptation (Engler-Chaouat \& Gilbert, 2007), or (3) if they are associated with a higher reproductive success, for instance when toxins are used as 
precursors for male pheromone synthesis (Hartmann et al., 2005; Trigo, 2011) or contribute to nuptial gifts (Cardoso \& Gilbert, 2007). Disentangling these effects will improve our understanding of the multiple forces shaping defense levels in prey, and hence their role in antipredator strategies such as mimicry.

\section{$\underline{\text { Estimating protection induced by chemical defenses using domestic chicks }}$}

While domestic chicks are not the natural predators of flying insects, both their capacity to modulate avoidance learning, and their ability to rapidly learn to reject toxic crumbs support their use as a model predator in many studies (Speed, 1999; Skelhorn \& Rowe, 2005, 2006a, b, c; Amézquita et al., 2013). We also observed relatively low individual variation among chicks in their avoidance learning (Figure 1), although variation was higher with the less protected species, as previously observed (Brower, 1958). Moreover, our findings using domestic chicks as a standardized predator are generally consistent with previous studies evaluating the behavior of other predators toward mimetic butterflies. Like this study, Arias et al. (2016a) found that M. polymnia was more palatable to birds (wild great tits), compared to $H$. numata and $H$. melpomene, but they found $H$. erato to be avoided more readily than we did, although still less than other species. Using caged silver-beaked tanagers (Ramphocelus carbo) and laboratory-reared Heliconius butterflies, Brower et al. (1963) showed that H. numata, H. melpomene, and H. erato were significantly better protected than $H$. doris. The discrepancy with our study lies in a lower estimated protection for $H$. doris and equal protection in H. erato and H. melpomene. This may stem from true differences in avoidance learning between studies, perhaps because of geographic variation in toxicity (Brazil vs. Peru) or from differences between laboratory-reared vs. wild-caught specimens. Alternatively, estimates might differ because variation in certain visual components of the warning signal such as pattern, size, or behavior displayed by the live butterflies, as used by Brower et al. (1963), could affect predator avoidance response. We believe that the number of "prey items" required for domestic chicks to completely avoid a prey species should allow a more ecologically relevant estimation of prey defenses (Rowland et al., 2017) than the use of disgust behavior as previously used (Brower et al., 1963; Arias et al., 2016a). Although our methodology cannot enable us to dissect the proximal causes of behavioural differences among chicks (sensitivity of gustatory 
receptors, visual perception, toxin tolerance, cognitive capacities, etc.; see Ruxton et al., 2018 for a review) it allows us to estimate the impact of variation in chemical defenses on prey survival, and explore its implications for the evolution of defenses in mimetic communities. Finally, the method presented relies on widely available domestic chicks and little equipment, and therefore offers the advantage of being easily applicable to a variety of organisms and enables direct comparisons between different studies when the same strain of chick is used (see Rowland et al., 2017).

\section{Conclusions}

Here, using a model predator, we provide evidence that the protection associated with the perception of natural chemical defenses by predators does not increase proportionately with the concentration of toxin. Avoidance learning plateaus above a certain threshold of toxin concentration. Above this level, the range of toxin concentrations is not readily explained by increased protection benefits, but perhaps by other ecological processes or even, in the absence of cost associated with toxin accumulation, simply by neutral processes. Our results suggest that if prey species within a mimicry ring cannot be readily distinguished by predators on the basis of their visual signals, then most well-defended species are expected to make a similar per capita contribution to the avoidance learning of their warning signal by predators. By contrast, only a small proportion of species with markedly lower toxin content elicited the slower avoidance learning that might indicate a lower per capita contribution to warning signal efficiency.

Data archival: Data are available in the linked Mendeley data repository.

Acknowledgments: We thank M. McClure, N. Rosser and M. Tuatama for their help with the logistics of the project; M. Veillette for her comments on manuscript drafts. We also thank the Peruvian government for providing the necessary research authorizations (permit: 002-2015-SERFORDGGSPFFS) and the Gobierno Regional San Martin PEHCBM for the authorization to perform research within the Cordillera Escalera Conservation Area (permit: 124-2016-GRSM/PEHCBMDMA/EII-ANP/JARR). This research was supported by a Marie Sklodowska-Curie fellowship (FITINV, 655857) to MC, a French National Agency for Research (ANR) grant (DOMEVOL, ANR13-JSV7-0003-01) and an 'Emergence' grant from Paris city council to VL, and by a European 
4

\section{References}

Amézquita, A., Castro, L., Arias, M., González Montoya, M. \& Esquivel, C. (2013). Field but not lab paradigms support generalisation by predators of aposematic polymorphic prey: The Oophaga histrionica complex. Evolutionary Ecology, 27, 769-782.

Arias, M., Mappes, J., Théry, M. \& Llaurens, V. (2016a). Inter-species variation in unpalatability does not explain polymorphism in a mimetic species. Evolutionary Ecology, 30, 419-433.

Arias, M., Meichanetzoglou, A., Elias, M., Rosser, N., de-Silva, D.L., Nay, B. et al. (2016b). Variation in cyanogenic compounds concentration within a Heliconius butterfly community: does mimicry explain everything? $B M C$ Evolutionary Biology, 16, 272.

Aubier, T., Joron, M. \& Sherratt, T.N. (2017). Mimicry among unequally defended prey species should rarely be parasitic if predators adopt the optimal sampling strategy. The American Naturalist, 189, 267-282.

Balogh, A.C.V., Gamberale-Stille, G. \& Leimar, O. (2008). Learning and the mimicry spectrum: from quasi-Bates to superMüller. Animal Behaviour, 76, 1591-1599.

Barbosa, P., Gross, P. \& Kemper, J. (1991). Influence of plant allelochemicals on the tobacco hornworm and its parasitoid, Cotesia congregata. Ecology, 72, 1567-1575.

Baxter, S.W., Nadeau, N.J., Maroja, L.S., Wilkinson, P., Counterman, B.A., Dawson, A. et al. (2010). Genomic hotspots for adaptation: The population genetics of Müllerian mimicry in the Heliconius melpomene clade. PLoS Genetics, 6.

Beccaloni, G.W. (1997). Vertical stratification of ithomiine butterfly (Nymphalidae : Ithomiinae) mimicry complexes: the relationship between adult flight height and larval host-plant height. Biological Journal of the Linnean Society, 62 , 313-341.

Brower, J.V.Z. (1958). Experimentalstudies of mimicry in some North American butterflies: Part II. Battus philenor and Papilio troilus, P. polyxenes and P. glaucus. Evolution, 12, 123-136.

Brower, L.P., Brower, J.V.Z. \& Collins, C.T. (1963). Experimental studies of mimicry. 7. Relative palatability and Müllerian mimicry among Neotropical butterflies of the subfamily Heliconiinae. Zoologica, 48, 65-84.

Brown, J.K.S. (1981). The biology of Heliconius and related genera. Annual Review of Entomology, 26, 427-457.

Campbell, B.C. \& Duffey, S.S. (1979). Tomatine and parasitic wasps: Potential incompatibility of plant antibiosis with biological control. Science, 205, 700-702.

Cardoso, M.Z. \& Gilbert, L.E. (2007). A male gift to its partner? Cyanogenic glycosides in the spermatophore of longwing butterflies (Heliconius). Naturwissenschaften, 94, 39-42.

Chai, P. (1996). Butterfly visual characteristics and ontogeny of responses to butterflies by a specialized tropical bird. Biological Journal of the Linnean Society, 59, 37-67.

Chouteau, M. \& Angers, B. (2011). The role of predators in maintaining the geographic organization of aposematic signals. The American Naturalist, 178, 810-817.

Chouteau, M., Arias, M. \& Joron, M. (2016). Warning signals are under positive frequency-dependent selection in nature. Proceedings of the National Academy of Sciences of the United States of America, 113, 2164-2169.

Counterman, B.A., Araujo-Perez, F., Hines, H.M., Baxter, S.W., Morrison, C.M., Lindstrom, D.P. et al. (2010). Genomic hotspots for adaptation: The population genetics of Müllerian mimicry in Heliconius erato. PLoS Genetics, 6(2): e1000796.

Demidenko, E., Glaholt, S.P., Kyker-Snowman, E., Shaw, J.R. \& Chen, C.Y. (2017). Single toxin dose-response models revisited. Toxicology and applied pharmacology, 314, 12-23.

DeVries, P.J. (1987). The butterflies of Costa Rica and their natural history, Vol. I: Papilionidae, Pieridae, Nymphalidae. Princeton University Press, Princeton.

Engler-Chaouat, H.S. \& Gilbert, L.E. (2007). De novo synthesis vs. sequestration: negatively correlated metabolic traits and the evolution of host plant specialization in cyanogenic butterflies. Journal of Chemical Ecology, 33, 25-42. 
Finkbeiner, S.D., Briscoe, A.D. \& Reed, R.D. (2012). The benefit of being a social butterfly: communal roosting deters predation. Proceedings of the Royal Society B-Biological Sciences, 279, 2769-2776.

Finkbeiner, S.D., Salazar, P.A., Nogales, S., Rush, C.E., Briscoe, A.D., Hill, R.I. et al. (2018). Frequency dependence shapes the adaptive landscape of imperfect Batesian mimicry. Proceedings of the Royal Society B: Biological Sciences, 285, 20172786.

Gamberale-Stille, G. \& Guilford, T. (2004). Automimicry destabilizes aposematism: predator sample-and-reject behaviour may provide a solution. Proceedings of the Royal Society B-Biological Sciences, 271, 2621-2625.

Gittleman, J.L. \& Harvey, P.H. (1980). Why are distasteful prey not cryptic? Nature, 286, 149.

Hartmann, T., Theuring, C., Beuerle, T., Bernays, E.A. \& Singer, M.S. (2005). Acquisition, transformation and maintenance of plant pyrrolizidine alkaloids by the polyphagous arctiid Grammia geneura. Insect Biochemistry and Molecular Biology, 35, 1083-1099.

Holloway, G.J., de Jong, P.W., Brakefield, P.M. \& de Vos, H. (1991). Chemical defence in ladybird beetles (Coccinellidae). I. Distribution of coccinelline and individual variation in defence in 7-spot ladybirds (Coccinella septempunctata). Chemoecology, 2, 7-14.

Huheey, J.E. (1976). Studies in warning coloration and mimicry .7. Evolutionary consequences of a batesian-müllerian spectrum - model for müllerian mimicry Evolution, 30, 86-93.

Ihalainen, E., Lindstrom, L., Mappes, J. \& Puolakkainen, S. (2008). Can experienced birds select for Mullerian mimicry? Behavioral Ecology, 19, 362-368.

Joron, M. (2005). Polymorphic mimicry, microhabitat use, and sex-specific behaviour. Journal of Evolutionary Biology, 18, 547-556.

Joron, M., Papa, R., Beltran, M., Chamberlain, N., Mavarez, J., Baxter, S. et al. (2006). A conserved supergene locus controls colour pattern diversity in Heliconius butterflies. PLoS Biol, 4, e303.

Kapan, D.D. (2001). Three-butterfly system provides a field test of mullerian mimicry. Nature, 409, 338-340.

Kazemi, B., Gamberale-Stille, G., Tullberg, Birgitta S. \& Leimar, O. (2014). Stimulus Salience as an Explanation for Imperfect Mimicry. Current Biology, 24, 965-969.

Lampert, E.C., Dyer, L.A. \& Bowers, M.D. (2010). Caterpillar chemical defense and parasitoid success: Cotesia congregata parasitism of Ceratomia catalpae. Journal of Chemical Ecology, 36, 992-998.

Lampert, E.C., Zangerl, A.R., Berenbaum, M.R. \& Ode, P.J. (2008). Tritrophic effects of xanthotoxin on the polyembryonic parasitoid Copidosoma sosares (Hymenoptera: Encyrtidae). Journal of Chemical Ecology, 34, 783-790.

Langham, G.M. (2004). Specialized avian predators repeatedly attack novel color morphs of Heliconius butterflies. Evolution, 58, 2783-2787.

Lindstrom, L., Lyytinen, A., Mappes, J. \& Ojala, K. (2006). Relative importance of taste and visual appearance for predator education in Mullerian mimicry. Animal Behaviour, 72, 323-333.

Mallet, J. (1999). Causes and consequences of a lack of coevolution in mullerian mimicry. Evolutionary Ecology, 13, 777806.

Mallet, J. (2001). Mimicry: An interface between psychology and evolution. Proceedings of the National Academy of Sciences, 98, 8928-8930.

Mallet, J. \& Barton, N.H. (1989). Strong natural-selection in a warning-color hybrid zone. Evolution, 43, 421-431.

Mappes, J., Kokko, H., Ojala, K. \& Lindström, L. (2014). Seasonal changes in predator community switch the direction of selection for prey defences. Nature communications, 5, 5016-5016.

Merrill, R.M., Dasmahapatra, K.K., Davey, J.W., Dell'Aglio, D.D., Hanly, J.J., Huber, B. et al. (2015). The diversification of Heliconius butterflies: what have we learned in 150 years? Journal of Evolutionary Biology, 28, 1417-1438.

Müller, F. (1878). Über die vortheile der mimicry bei schmetterlingen. Zoologischer Anzeiger, 1, 54-55.

Nishida, R. (1994). Sequestration of plant secondary coumpounds by butterflies and moths. Chemoecology, 5, 127-138.

Nishida, R. (2002). Sequestration of defensive substances from plants by Lepidoptera. Annual Review of Entomology, 47.

Ohsaki, N. (1995). Preferential predation of female butterflies and the evolution of batesian mimicry. Nature, $378,173$.

Pekar, S., Petrakova, L., Bulbert, M.W., Whiting, M.J. \& Herberstein, M.E. (2017). The golden mimicry complex uses a wide spectrum of defence to deter a community of predators. eLife, 2017;6:e22089.

Pinheiro, C.E.G. (1996). Palatablility and escaping ability in Neotropical butterflies: tests with wild kingbirds (Tyrannus melancholicus, Tyrannidae). Biological Journal of the Linnean Society, 59, 351-365.

Pinheiro, J., Bates, D., DebRoy, S., Sarkar, D. \& Team., R.C. (2017). nlme: Linear and nonlinear mixed effects models. $R$ package version 3.1-131, https://CRAN.R-project.org/package=nlme. . 
R Development Core Team (2013). R: A language and environment for statistical computing. $R$ Foundation for Statistical Computing, Vienna, Austria. URL http://www.R-project.org/.

Rowland, H.M., Fulford, A.J.T. \& Ruxton, G.D. (2017). Predator learning differences affect the survival of chemically defended prey. Animal Behaviour, 124, 65-74.

Rowland, H.M., Ihalainen, E., Lindstrom, L., Mappes, J. \& Speed, M.P. (2007). Co-mimics have a mutualistic relationship despite unequal defences. Nature, 448, 64-67.

Rowland, H.M., Mappes, J., Ruxton, G.D. \& Speed, M.P. (2010). Mimicry between unequally defended prey can be parasitic: evidence for quasi-Batesian mimicry. Ecology Letters, 13, 1494-1502.

Ruxton, G.D., Sherratt, T.N., Allen, W.L. \& Speed, M.P. (2018). Avoiding attack: The evolutionary ecology of crypsis, aposematism, and mimicry. Second edn. Oxford University Press, Oxford U.K.

Sherratt, T.N. (2008). The evolution of Mullerian mimicry. Naturwissenschaften, 95, 681-695.

Sherratt, T.N., Whissell, E., Webster, R. \& Kikuchi, D.W. (2015). Hierarchical overshadowing of stimuli and its role in mimicry evolution. Animal Behaviour, 108, 73-79.

Sillén-Tullberg, B. (1985). Higher survival of an aposematic than of a cryptic fom of a distasteful bug. Oecologia, 67, 411415.

Sime, K. (2002). Chemical defence of Battus philenor larvae against attack by the parasitoid Trogus pennator. Ecological Entomology, 27, 337-345.

Skelhorn, J., Halpin, C.G. \& Rowe, C. (2016). Learning about aposematic prey. Behavioral Ecology, 27, 955-964.

Skelhorn, J. \& Rowe, C. (2005). Tasting the difference: do multiple defence chemicals interact in Müllerian mimicry? Proceedings of the Royal Society B: Biological Sciences, 272, 339-345.

Skelhorn, J. \& Rowe, C. (2006a). Avian predators taste-reject aposematic prey on the basis of their chemical defence. Biology Letters, 2, 348-350.

Skelhorn, J. \& Rowe, C. (2006b). Prey palatability influences predator learning and memory. Animal Behaviour, 71, 11111118.

Skelhorn, J. \& Rowe, C. (2006c). Taste-rejection by predators and the evolution of unpalatability in prey. Behavioral Ecology and Sociobiology, 60, 550-555.

Skelhorn, J. \& Ruxton, G.D. (2008). Ecological factors influencing the evolution of insects' chemical defenses. Behavioral Ecology, 19, 146-153.

Smith, D.A.S. (1979). The significance of beak marks on the wing of an aposematic butterfly. Nature, 281, 215-216.

Speed, M.P. (1993). Müllerian mimicry and the psychology of predation. Animal Behaviour, 45, 571-580.

Speed, M.P. (1999). Batesian, quasi-Batesian or Müllerian mimicry? Theory and data in mimicry Research. Evolutionary Ecology, 13, 755-776.

Speed, M.P., Ruxton, G.D., Mappes, J. \& Sherratt, T.N. (2012). Why are defensive toxins so variable? An evolutionary perspective. Biological Reviews, 87, 874-884.

Stuckert, A.M.M., Venegas, P.J. \& Summers, K. (2014). Experimental evidence for predator learning and Müllerian mimicry in Peruvian poison frogs (Ranitomeya, Dendrobatidae). Evolutionary Ecology, 28, 413-426.

Trigo, J.R. (2011). Effects of pyrrolizidine alkaloids through different trophic levels. Phytochemistry Reviews, 10, 83-98.

Trigo, J.R. \& Brown, K.S. (1990). Variation of pyrrolizidine alkaloids in Ithomiinae: A comparative study between species feeding on Apocynaceae and Solanaceae. Chemoecology, 1, 22-29.

Wiklund, C. \& Järvi, T. (1982). Survival of distasteful insects after being attacked by naïve birds: a reappraisal of the theory of aposematic coloration evolving through individual selection. Evolution, 36, 998-1002.

Williams, B.L. \& Brodie, E.D. (2003). Coevolution of deadly toxins and predator resistance: Self-assessment of resistance by garter snakes leads to behavioral rejection of toxic newt prey. Herpetologica, 59, 155-163. 


\section{Supplementary Information}

2 Table S1: Statistical analysis of avoidance learning experiments based entirely on unpalatable

3 prey. Here we have discarded data on the total number of palatable crumbs consumed of the experimental colour in the initial presentation, so that trial 0 (formerly trial 1) begins with the first presentation of unpalatable crumbs. The same range of candidate non-linear models were fitted to the consumption of treated crumbs over time by chicks as in the main text (we have kept the same order for comparability; $\mathrm{nc}=$ no convergence). Once again most parsimonious models involve the fixed effects of trial (model 1 vs model 7, LR = 731.28, $\mathrm{P}<0.001$ ) but not crumb colour (model 1 vs model $2, \mathrm{LR}=$ $1.93, \mathrm{P}=0.165)$. In addition, there was evidence of significant variation in the rate at which individual chicks avoided treated crumbs made from different butterfly species (model 1 vs model 6, LR =545.42, $\mathrm{P}<0.001)$

\begin{tabular}{|l|l|l|l|l|}
\hline Model number & $\begin{array}{l}\text { Model for treated prey } \\
\text { consumption over trials } \\
(\boldsymbol{a}, \boldsymbol{b}, \boldsymbol{c}, \boldsymbol{f} \text { parameters) }\end{array}$ & $\begin{array}{l}\text { Random effect } \\
\text { parameter } \\
(\sim \text { species/bird) }\end{array}$ & $\mathbf{d f}$ & AIC \\
\hline 1 & $b^{*} \exp \left(-c^{*}\right.$ trial) & $c$ & 5 & 3317.4 \\
\hline 2 & $b^{*} \exp \left(-c^{*}\right.$ trial) $+f^{*}$ colour & $c$ & 6 & 3321.3 \\
\hline 3 & $a+b^{*} \exp \left(-c^{*}\right.$ trial) & $c$ & 6 & $n c$ \\
\hline 4 & $a+b^{*} \exp \left(-c^{*}\right.$ trial) & $a$ & 6 & 3526.2 \\
\hline 5 & $a+b^{*} \exp \left(-c^{*}\right.$ trial) & $b$ & 6 & 3444.6 \\
\hline 6 & $b^{*} \exp \left(-c^{*}\right.$ trial) & - & 3 & 3858.8 \\
\hline 7 & $a$ & $a$ & 4 & 4046.7 \\
\hline
\end{tabular}

\section{Figure S1a,b}

Plot of the estimate of the total number of treated crumbs consumed by chicks when the first presentation of palatable crumbs was included or excluded from the analysis (in 62 cases where convergence was obtained). (a) entire data set, (b) the data set without five high values. Here the fitted curves were similar so that the two estimates were highly correlated $\left(F_{1,60}=3107, R^{2}=0.98, P<\right.$ 0.001). 
2

3

4

5

6

7

8

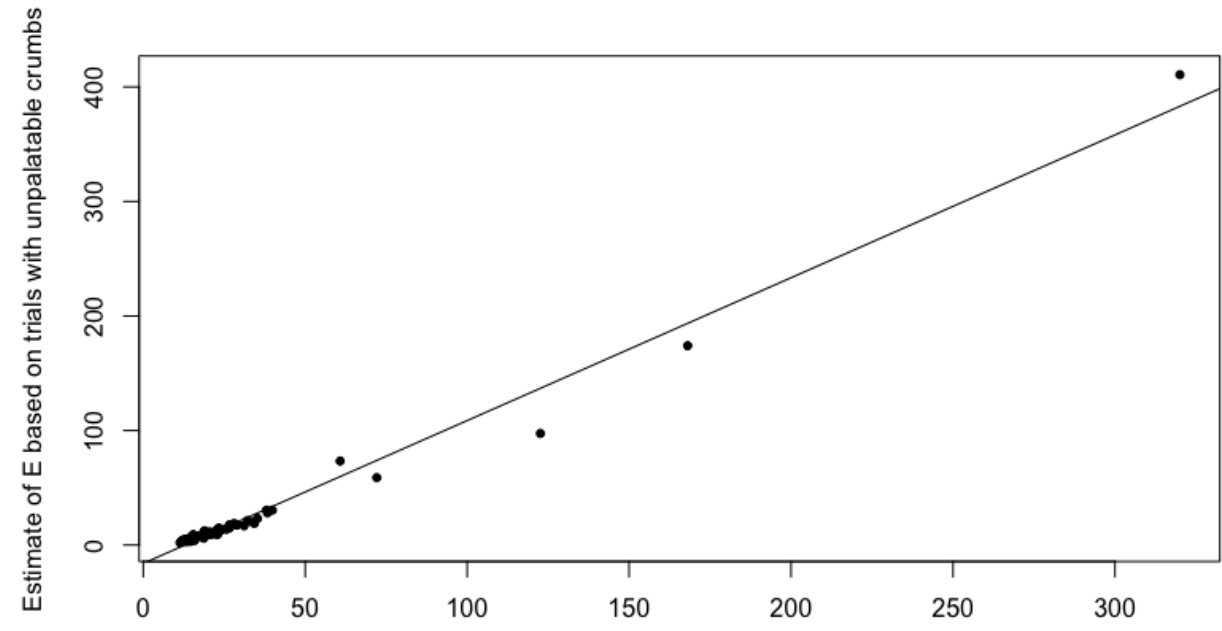

Estimate of $E$ based on all trials

(b)
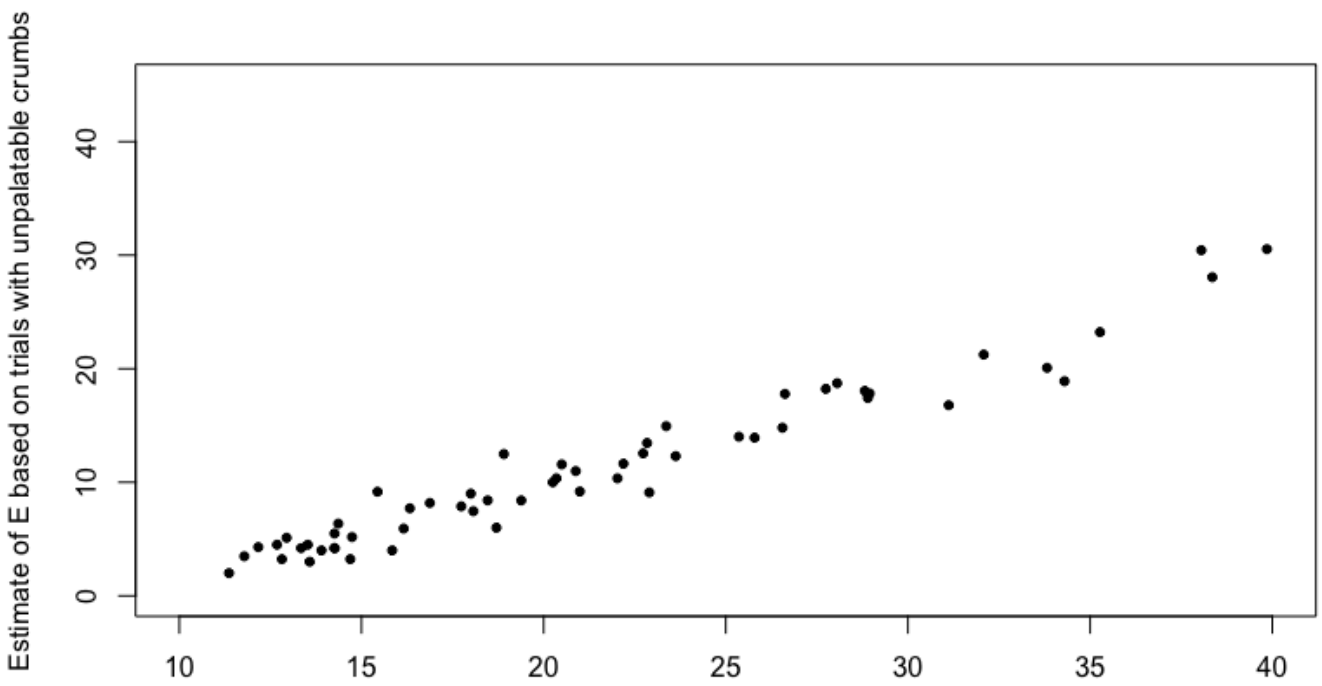

Estimate of $E$ based on all trials

9

10 Estimates of $\mathrm{E}$ (when the first presentation was removed) were not different among defended butterfly

11 species $\left(F_{12,49}=1.203 ; p=0.308\right)$ when analysed conjointly. When analysed by mimicry rings, results are similar to the one presented in the main text with only the mimicry rings including H. erato displayed significant variation of E: 'postman' ring $\left(F_{1,9}=5.873 ; p=0.038\right)$, and 'dennis-ray' ring $\left(F_{4,18}=3.583\right.$; $p=0.025)$.

15 Finally, we found the same relationship between mean toxicity levels for each species (i.e. $\left.C_{N A C N}\right)$ and 16 the resulting protection from predator as estimated with $E$. The exponential decay model (asymptotic 
1 decrease) provided the best fit to the data (AICs: intercept only model 51.09; linear model 42.75;

2 exponential model 30.45) and explained more variation than the linear model with the same number of 3 terms $\left(F_{1,5}=65.581, p<0.001\right)$.

4

5

6 